\title{
LOS DIENTES DE RAQUEL DE GABRIEL JIMÉNEZ EMÁN: UN ABISMO EN MINIATURA
}

Teeth of Raquel of Gabriel Jiménez Emán:

an abyss in miniature

Wilfredo José Rafael Illas Ramírez ${ }^{1}$

Fecha de recepción: 02 de septiembre de 2016

Fecha de aceptación: 10 de octubre de 2016 


\section{Resumen}

El presente artículo se plantea como objetivo, comprender los rasgos de la escritura minificcional de Gabriel Jiménez Emán a partir de su obra Los dientes de Raquel, cuyos rasgos son esbozados en tres dimensiones: a) el papel que juega, en la arquitectura del texto, el inicio como pieza fundamental en la economía lingüística y en la concisión discursiva, b) la importancia del final como efecto paralizante, golpe del ingenio creador y posibilidad de múltiples significados; $y$ c) el empleo del suspenso y lo fantástico como recurso fundamental en la construcción de atmósferas absurdas, irónicas, paródicas, onírica y misteriosas. A partir de una comprensión hermenéutica, se plantea no solo la aproximación a las estrategias narrativas de Jiménez Emán, sino que el examen de los rasgos constitutivos de la minificción como género emergente, permite advertir el carácter de ruptura, fragmentariedad, juego, velocidad, multiplicidad y simultaneidad que convierten al universo minificcional en un abismo en miniatura.

Palabras clave: Gabriel Jiménez Emán, Los dientes de Raquel, minificción.

\section{Abstract}

This article aims at understanding the features of Gabriel Jimenez Eman's minifictional writing from his work Los dientes de Raquel, which are outlined in three dimensions: a) the role played in the architecture of the text, by the starting as a cornerstone in linguistic economy, and discursive concision; $b$ ) the importance of the final as paralyzing effect, stroke of the creative genius and the possibility of multiple meanings; and c) the use of suspense and fantasy as fundamental resources in the construction of absurd, ironic, parodic, dreamlike and mysterious atmospheres. From a hermeneutic understanding, it is presented not only the approach to Jimenez Eman's narrative strategies, but also the examination of the minifiction constituent elements as emerging genre, allowing to observe the character of rupture, fragmentation, game, speed, multiplicity and simultaneity that make the minificcional universe a miniature abyss.

Keywords: Gabriel Jimenez Eman, Los dientes de Raquel, minifiction. 


\section{Introducción}

No hay nada menos apropiado para aproximarse a una obra de arte que las palabras de la crítica: de ellas se derivan siempre malentendidos más o menos desafortunados. Las cosas no son tan comprensibles ni tan

formulables como se nos quiere hacer creer casi siempre; la mayor parte de los acontecimientos son indecibles, se desarrollan en un ámbito donde nunca ha penetrado ninguna palabra. Y lo máximamente indecible son las obras de arte, existencias llenas de misterio, cuya vida, en contraste con la nuestra, tan efímera, perdura.

Rainer Maria Rilke

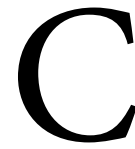
on su libro Los dientes de Raquel, Gabriel Jiménez Emán no solo inaugura lo que sería su carrera de escritor, sino que además exhibe, como búsqueda narrativa, una pasión por la brevedad. De allí que este libro constituya una obra representativa y fundacional de la minificción venezolana y es que, la cortedad es auxiliada además por el humor, la fantasía y lo absurdo. En su conjunto, el universo narrativo construido por Jiménez Emán en este libro, apuesta por un golpe final que sacude al lector y lo lleva a experimentar un éxtasis de asombro pero también de inquietud ante los múltiples escenarios de comprensión que el texto sugiere. De esta forma, Los dientes de Raquel son la construcción de un pequeño mundo desde la economía lingüística y narrativa, pero paralelamente es amplio, no solo en recursos, sino en posibilidades de lectura. Es este uno de los rasgos más fundamentales de la minificción, textos que conjugan a un mismo tiempo una relación de antítesis que se da entre brevedad y amplitud.

Aunado a ello, esta obra está sostenida sobre un carácter imaginativo que cuestiona las reglas de la lógica hasta sustituirla por fuertes paradojas, ironías, abismos e incoherencias que descansan en un juego permanente entre sueño y realidad. Con propiedad ha afirmado el mismo Jiménez Emán (1982: 6): “Me interesan los estados límite [...] los estados latentes de la conciencia humana como el sueño". Ante esta afirmación no resulta extraño que en esta obra se teja ese asombro sostenido en lo irracional, en la dilución de los esquemas coherentes, en el juego imaginario y en la confusión que suscita el absurdo. Una obra que se percibe desde una búsqueda surrealista que se mueve en lo circular, la síntesis, la sorpresa y el juego para confundir al lector, quien sobrevive al texto a través de una carcajada. Por esta razón, Los dientes de Raquel, responden a ese interés de escapar de la realidad para evadirse, jugar, conocer mundos posibles y alternos; en fin, es un escenario narrativo propicio para refugiarse en el deleite que produce ese caos asombroso, confuso y extraño que mueve todas las coordenadas caracterizadoras de esta obra.

La aproximación a los textos del libro Los dientes de Raquel, que se ha planteado para este trabajo, se enfocará en tres dimensiones: a) el inicio como enganche del lector, b) el desenlace como golpe final; y, c) el suspenso como atmósfera del relato minificcional. Como se observa, todas las categorías a objeto de análisis centraran su interés en el papel activo del lector. De esta forma, seducción, asombro y sacudida parecen ser las transiciones narrativas por las cuales se desplaza el lector; pero, además, parecen ser ins- 
tancias recurrentes que sustentan la creación minificcional. Junto a ello, el tema fantástico plantea tres desafíos: diversificar las posibilidades interpretativas del texto, suscitar una atmósfera de extrañeza que vehicula el suspenso y lo absurdo; y, relacionar los elementos narrativos (apenas pincelados) desde un desconcierto en el cual la ironía, el humor, la parodia y el juego desembocan en ruptura, fragmentariedad y asombro; todo ello confeccionado desde una brevedad extrema y a partir de unos elementos comprimidos que, paradójicamente, estallan en una multiplicidad de sentidos y significados que se despliegan del tránsito por estos universos minificcionales....abismos en miniatura. Es importante aclarar que para este trabajo el término abismo se asume no desde el relato enmarcado como puede entenderse a partir de la expresión francesa mise en abyme, sino como espacio profundo recreado por J.R.R Tolkiem en el abismo de Helm. De esta forma, se apuesta con la expresión abismo en miniatura, a una construcción alegórica que alude a esa dimensión narrativa insondable en la cual el texto minificcional adquiere infinitas posibilidades de construcción y múltiples formas de comprensión.

\title{
1. El inicio como pieza clave: concisión, enganche y atmósfera
}

\author{
Me convenzo ahora de que la brevedad es una entelequia \\ cuando leo una línea y me parece más larga que mi propia vida, \\ y cuando después leo una novela y me parece más breve \\ que la muerte. Gabriel Jiménez Emán.
}

Uno de los rasgos más fundamentales de la minificción es la brevedad conseguida, en parte, por la concisión, por el empleo de un lenguaje preciso que ahorra detalles descriptivos, por la presentación de una anécdota comprimida (Rojo, 2009) que, en todos los casos, suprime elementos o apenas los matiza y por la economía manifiesta que es síntoma y exigencia de unos textos tan cortos en los que unas cuantas palabras resultan suficientes para desarrollar los complejos temáticos y ficcionales por los que apuesta simultáneamente el pequeño e infinito escenario narrativo.

En este sentido, el inicio del texto en la minificción posee una importancia capital, ya que no solo debe responder a las exigencias compartidas con los cuentos convencionales, tales como: proyectarse hasta el final del cuento y atrapar el interés del lector; sino que, además, tiene como reto la necesidad de mostrar, sin mayores adornos, las acciones de los personajes o las miradas reflexivas del autor; es decir, las primeras líneas ya deben apuntar a desnudar al personaje y a sus manifestaciones; 0 , a develar el pensamiento y perspectiva reflexiva del creador; en cualquier caso, lo vital en cualquier cuento y, más aún, en aquellos de brevedad extrema como suelen ser los mundos minificcionales, consiste básicamente en proporcionar un comienzo que sirva para introducir al lector velozmente en la anécdota, trama o reflexión; y que junto a ello despierte en él un sinfín de emociones e intereses que lo conecten con la mínima historia, lo envuelvan en la atmósfera de suspenso que queda cifrada desde la primera frase, le permitan la entrada a un espacio narrativo austero que vertiginosamente se convierte en un abismo de significados y sentidos; en fin, lo involucren en esa incógnita para resolver entonces el acertijo que, a modo de laberinto, se ha confeccionado en el espacio minificcional. Veamos dos ejemplos que ilustren estos planteamientos, el primero sería precisamente el texto minificcional Los dientes de Raquel: 
RAQUEL mordió una manzana, y todos sus dientes quedaron en ella. Fue a su casa con la boca sangrando a avisarle a su mamá. La mamá vino corriendo asustada a buscar los dientes de Raquel, y cuando llegó, los dientes se habían comido la manzana.

La mamá quiso recogerlos, pero los dientes se levantaron y se comieron a Raquel y a la mamá.

Después, los dientes volvieron a la boca de Raquel, quien muy hambrienta corrió a pedirle a su mamá que le comprara una manzana. (73)

Obsérvese que en este texto minificcional (cercano a lo que sería el minicuento), con su frase inicial "Raquel mordió una manzana y todos sus dientes quedaron en ella", no solo nos introduce inmediatamente en la trama, sino que crea en un solo momento una atmósfera de misterio, suspenso y maravilla. Hay allí una conexión radical entre realidad y primeros indicios de posibilidad fantástica. Desde esta frase se asegura el interés del lector quien además de sortear los desafíos que se proyectan por el absurdo, deberá ir resolviendo un conjunto de acertijos: ¿cómo era la manzana?, ¿por qué los dientes quedaron en ella?, y ¿qué pasará con Raquel y sus dientes?, entre otros que se susciten a partir de un amplio poder de sugerencia, que de por sí, ya proyecta esa frase inicial. Ese conjunto de incógnitas fortalecen un clima de intensidad en este pequeño universo minificcional y vienen a convertir en detective a ese lector atento al que se le han desplazado todas las certezas y ahora debe arribar a una posible explicación que le dé acceso (sentido) a ese extraño suceso, trazado como esencia y meta de lo que será su propio desafío de lectura. Veamos otro ejemplo, esta vez el texto minificcional Los brazos de Kalym:

KALYM SE arrancó los brazos y los lanzó a un abismo. Al llegar a su casa, su mujer le preguntó sorprendida: “¿Qué has hecho con tus brazos?”.

-Me cansé de ellos y me los arranqué-respondió Kalym.

-Tendrás que ir a buscarlos; vas a necesitarlos para el almuerzo. ¿Dónde están?

-En un abismo, muy lejos de aquí.

- ¿Y cómo has hecho para arrancártelos?

-Me despegué el derecho con el izquierdo, y el izquierdo con el derecho.

-No puede ser -respondió su mujer- pues necesitabas el izquierdo para arrancarte el derecho, pero ya te lo habías arrancado.

-Ya lo sé mujer; mis brazos son algo muy extraño. Olvidemos eso por ahora y vayamos a dormir- dijo Kalym abrazando a su mujer. (33)

Vemos como aquí se nos introduce al texto con la frase "Kalym se arrancó los brazos y los lanzó al abismo". Por asalto el lector queda sumergido en la anécdota, la cual tiene una resolución aparente, ya se sabe que hizo Kalym con sus brazos; sin embargo, abre otro abanico de incógnitas en torno a este absurdo acontecimiento. El lector (por el susto, la perplejidad y el vértigo que le suscita este abismo en miniatura) ha perdido toda coordenada ante la búsqueda de una posibilidad viable que explique, invocando a una racionalidad lógica, el asombroso suceso. El inicio es mordaz e impactante, genera una atmósfera de suspenso y un clima maravilloso y misterioso, en que la fantasía dispone a capricho 
las fronteras y cruces entre realidad y ficción. Igual al texto anterior, mágicamente la razón perdida vuelve a rescatar el hilo anecdótico (los dientes vuelven a la boca de Raquel; o, no puede ser -respondió su mujer), pero paradójicamente, no se organizan los hechos, al contrario, hay más desconcierto, se trastoca toda posibilidad de coherencia, queda solo una carcajada que augura el carácter cíclico, fragmentario y lúdico de la abismal esfera minificcional.

Es evidente que este inicio es cautivador, atrapa la atención del lector por el absurdo y lo inquietante, instancias que desembocan en intriga, enigma, sorpresa y extrañeza. La concisión en ambos ejemplos es violenta y los inicios se constituyen como antesala a la creación minificcional cuya atmósfera está signada por las trampas a la realidad, por lo desquiciante, onírico, surrealista e incógnito, lo cual, naturalmente, suscita en nuestro lector, parálisis e impacto. Esa primera frase pareciese resumir la historia, de hecho, en ella se condensa el nudo temático, conflicto y esencia anecdótica. Luego de ella, lo que resta es enterarse de una explicación que clarifique (o confunda) la comprensión de ese suceso maravilloso y, fundamentalmente, desconcertante... un acertijo indescifrable.

Como se observa, son inicios que súbitamente nos introducen en un acontecimiento inexplicable, reservando el resto de la minúscula historia a tantear pistas que "aclaren" algunos posibles sentidos y significados. Es precisamente ese golpe súbito el que atrapa y encanta al lector a partir de un cosmos narrativo sustentado en lo absurdo que no puede más que generar atmósferas desquiciantes, de asombro y suspenso que exigen permanentemente la cooperación del lector para reescribirse y resignificarse (a modo de caleidoscopio) desde cada posibilidad de lectura. La primera frase del relato minificcional, evidentemente, resulta ser fundamental para alcanzar la concisión, delinear algunos matices narrativos y portar una intensa carga de significados y sugerencias que se van articulando en la multiplicidad de lecturas posibles. Exigen un delicado tratamiento artístico para configurar, desde la incógnita, el suspenso y lo fantástico, el clima y la tensión anecdótica, lo que hace que el pequeño abismo minificcional resulte atractivo, impacte y suscite múltiples formas de significar (leer) el texto y sus coordenadas narrativas. Incertidumbre y extrañeza son los ingredientes fundamentales con los que el inicio se constituye en pieza clave del texto minificcional.

Pareciese que estos inicios contienen toda la historia, y es que además de golpear y atrapar al lector, lo introducen de un solo tirón en las acciones, en el mundo de los personajes, en los argumentos y atmósferas. A modo de Aleph, en estos inicios ocurre todo simultáneamente, lo que le asigna a la minificción ese carácter mágico que cautiva a partir de los múltiples modos de lectura. Visto así, el inicio logra sumergir vertiginosamente al lector en el texto, atrapar su interés, generar las atmósferas, alcanzar la concisión, configurar las coordenadas narrativas que sustentan el pequeño universo minificcional y proyectar desde la primera palabra y hasta la última, un abanico de múltiples sentidos y significados que se despliegan a partir del ejercicio lector. 


\title{
2. El desenlace... golpe final
}

\author{
Se miente más de la cuenta por falta de fantasía: \\ también la verdad se inventa. \\ Antonio Machado
}

Al realizar una aproximación a los roles que activamente ejecuta el lector en la co-construcción de la obra, no solo examinamos las perspectivas teóricas propuesta por la estética de la recepción a través de los postulados de Wolfgang Iser, sino que advertimos cómo la arquitectura textual se consolida desde la participación del lector, desde sus competencias para completar la historia, reescribirla o darle un sentido a partir de sus particulares perspectivas de interpretación o de sus genuinos e inéditos lugares de lectura; en otras palabras, cómo se aventura en el ejercicio de rellenar los vacíos que el texto proyecta.

Es lugar común insistir en el rasgo polisémico y sugerente de la minificción; y es que, ciertamente, lo maravilloso de este emergente género literario es ese poder de sugerencia, esa proyección de múltiples escenarios de lectura, en fin, esa presencia reiterativa de espacios vacíos que convocan la participación del lector en su significación. Es a partir de este entramado producción-recepción, que se movilizan la creatividad, imaginación e ingenio tanto en la re-construcción de los complejos narrativos que constituyen el universo minificcional, como en el aprovechamiento de las múltiples posibilidades interpretativas que estos pequeños fragmentos ficcionales son capaces de desplegar. $\mathrm{Al}$ respecto, resultan a propósito las consideraciones de Iser (1987: 216) quien plantea:

Es la virtualidad de la obra la que da origen a su naturaleza dinámica, y ésta a su vez es la condición previa para los efectos que la obra suscita. A medida que el lector utiliza las diversas perspectivas que el texto le ofrece a fin de relacionar los esquemas y las "visiones esquematizadas" entre sí, pone a la obra en marcha, y este mismo proceso tiene como último resultado un despertar de reacciones en su fuero interno.

Queda desde ya deslindado un primer asunto: "El texto se actualiza, por lo tanto, solo mediante las actividades de una conciencia que lo recibe" (Iser, 1987: 87). En esta suerte texto y lector quedan unidos indisolublemente y el sello será el conjunto de actividades esbozadas dentro del proceso lector. Tres ideas deben ser rescatadas en este punto: a) actualizar el texto es traerlo al horizonte de la lectura, b) las actividades implicarían un cruce entre las coordenadas que constituyen al texto y los particulares horizontes de lectura que constituyen la conciencia del lector; y, c) cuya conciencia en su carácter dinámico se aventura a recibir el texto no en la inmovilidad de lo que dice, sino en la multiplicidad de posibilidades de significación que pueden desplegarse a partir de lo que calla (sugiere).

En esta dupla lector-texto, ¿dónde queda la obra? Es evidente que Iser (1987), reserva para la construcción conceptual "obra" el proceso que, desplegado por la lectura, permite el cruce entre las pistas o estrategias que el texto entrega (horizonte establecido) y la conciencia del lector (experiencias) dispuesta a recibirlo. El resultado del precitado cruce (horizonte futuro) será la obra, expresada por una instancia de co y re-creación en la cual se “actualizaría el potencial implícito del texto” (Iser, 1987: 101). 
Así, Iser (1987: 87) es enfático al expresar: “...de manera que la obra adquiere su auténtico carácter procesal solo en el proceso de su lectura”. Es evidente que la tríada relacional texto-obra-lector comienza a dar sus frutos epistémicos (teóricos y metodológicos) en el concierto de nuevas coordenadas que centrarían su atención en el ejercicio lector. Visto así, la obra se completa al cumplirse un proceso de lectura que haría definitivamente funcionar al texto desde la actividad del lector. Pareciese entonces que autor y lector quedan fundidos desde el juego que proporciona el horizonte textual, cuyo juego es suscitar y ejercer respectivamente, una dinámica de productividad (por ende recíproca) que, desprendida de la lectura, teje con nuevas exploraciones (significaciones) el tapiz de la obra.

Serían esas nuevas exploraciones, por una parte, lo no dicho; y por la otra, encontrándonos a nosotros mismos en las posibilidades de diálogo que pueden ser exploradas. Para Iser (1987: 88) "los vacíos introducen al lector en la acción". Es una idea recurrente en sus búsquedas y si se quiere la tesis central de su planteamiento. Los vacíos, lo no dicho, lo que el texto no terminó de aportar, proporciona tres ideas como valor agregado: a) genera expectativa, incertidumbre e interés, b) estimula la acción de la conciencia receptora hacia el ejercicio de la imaginación; y c) posibilita una dinámica de participación en la búsqueda de los múltiples sentidos y significados que, escudriñados en la lectura y en los cruces consecuentes, alcanza a desplegar el texto. Lo diseñado por el texto se actualiza permanentemente a partir del lugar de las indeterminaciones, ese lugar que, al ser rellenado, adquiere nuevas e infinitas posibilidades de significación. No se trata solo de que el encuentro texto - lector desencadene un proceso de significación, se trata además que el texto adquiere una dimensión inacabada que hace posible una permanente disposición de su arquitectura en la medida en la conciencia receptora suscite, genere o sugiera una multiplicidad de dimensiones.

En cada nueva aprehensión del texto se configuran nuevos horizontes de significación "horizonte futuro y vacío que debe llenarse", que nos hablan de tres estados fundamentales de la conciencia receptora: participación desde el proceso de lectura, actualización de lo implícito en el texto y significación de múltiples posibilidades que se alumbran del cruce lector-texto (producción de sentidos que dialogan con la conciencia representativa, con aquello que se ha aprehendido del texto). Para Iser (1987: 92) "Cada lectura deviene así una actualización individualizada del texto, en la medida que el espacio de relaciones débilmente determinado permite alumbrar configuraciones diferentes de sentido".

Lo que se recibe del texto desde la aprehensión sería la representación que, como imagen, nos figuramos del objeto. La existencia de dicha representación no es una proyección estática, antes bien, es dinámica, se reconfigura una y otra vez desde las coordenadas de la lectura y ello se debe a que se encuentra instalada en el territorio de la indeterminación, de allí que esa movilización constante desemboque en un ejercicio productivo. Dicho de otra forma, nuestro particular equipaje de lectura se estrecha con las señas que proporciona el texto generando así la producción de sentidos. El lector se funde ahora con unos síntomas significativos del texto que en definitiva son los propios síntomas que configuran el estado de su propia constitución comprensiva. Texto y lector pareciesen ser dos caras de la misma moneda receptora-productora. Y es que ya el texto diluye sus propias coordenadas y comienza a ser el mapa que: a) configuró la ruta de su lector y ahora es b) el camino transitado por el mismo.

Este entramado conceptual nos permite advertir tres ideas lúcidas para el asunto de la recepción: a) el texto proporcionó lugares indeterminados, pero también pistas, b) el lector llena los vacíos, pero incorpora sus propias expectativas; y c) la obra es un viaje de ida y retorno a un lugar incierto (destino de 
posibilidades) cuyos pasajeros quedan fundidos en una reciprocidad que - tal como refiere Iser (1987) - hace que el lector sea sujeto de esas ideas ajenas, en un diálogo lector-autor que se enlazan en una sola experiencia, esa que le permitió conocer a un otro y con esa conciencia, formularse a sí mismo. Es este el resultado más interesante de este deslinde, al construir los sentidos de un texto no solo actúo en el laberinto diseñado por un otro, sino que, al desentrañar por medio de una de las múltiples fórmulas, el camino a la salida, me he formulado, me he configurado en el propio proceso receptivo y por ende, en las diversas posibilidades de significación que al poner en diálogo con el texto, me revelan como transeúnte de ese universo. Tomando las palabras de Iser (1987: 104):

El texto abre un espacio que no es inmediatamente presente a nuestra conciencia. La constitución de sentido que ocurre en la lectura de un texto literario significa por eso no solo (como hemos discutido a propósito de la formación de configuraciones en la lectura) que se descubre lo no formulado en el texto para ocuparlo con los actos representativos del lector; la constitución de sentido significa además que en tal formulación de lo no formulado radica también la posibilidad de formularnos a nosotros mismos, descubriendo así lo que hasta entonces parecía sustraerse a nuestra conciencia. En este sentido la literatura ofrece la oportunidad de formularnos a nosotros mismos mediante la formulación de lo no formulado.

Si bien es cierto que el texto moviliza en el lector aspectos afectivos, cognitivos e intelectivos; también es cierto que esa movilización no es automática, pues requiere de la competencia, habilidad y audacia con la que actúe el lector en la construcción e interpretación del texto. Con razón afirma Iser (1987) que en definitiva todo proceso de lectura desemboca en el rol activo que debe protagonizar el lector en cuanto a recreación, re-construcción y re-significación de las complejas redes narrativas, ficcionales y temáticas que el texto proyecta. En fin, es el lector quien completa los vacíos textuales a partir de sus particulares horizontes interpretativos, desde las pistas que proyecta el texto y en atención a la propia experiencia de lectura. En este aspecto, resultan válidos los planteamientos que, en referencia a Iser, formula Gómez (1996: 252-253):

[...] un texto es un espacio inconcreto, lleno de posibilidades significativas y de remisiones extratextuales que se encuentran a la espera de su concreción. Para explicar la multiplicidad de probabilidades que un texto ofrece, Iser indica que el lector se le entrega un sistema de indeterminaciones -o de "vacíos" de significado- que tendrá que rellenar en conformidad con su experiencia; porque, al fin y al cabo, en un texto es tan importante la parte escrita como la no escrita, es decir, todo ese conjunto de ideas $\mathrm{y}$ de valores que se ponen en funcionamiento en cuanto se comienzan a recorrer las primeras líneas de un texto[...] Esos espacios vacíos son los que regulan la actividad representadora del lector y le permiten, sobretodo, coordinar las perspectivas dentro del texto. Por ello, toda lectura es un acto creativo y cada lectura es diferente [...]

A partir de los anteriores planteamientos se puede inferir que, aunque toda lectura es espacio propicio para re-construir/re-significar el texto, esta situación se proyecta con marcado énfasis dentro del espacio 
minificcional; y es que, dada la brevedad característica, estos pequeños fragmentos narrativos son verdaderos abismos ficcionales y, por consiguiente, son amplios y potenciales para suscitar la participación activa del lector en la búsqueda de significados. Para examinar el papel del lector en la co-construcción del abismo en miniatura que se plantea en cada mundo minificcional (absurdo, fragmentario, trasgresor, lúdico y de vertiginosa simultaneidad), continuaremos, ahora analizando el desenlace de estos textos, no solo como "golpe final del ingenio creador" (Rojo, 2009; Zavala, 2005), sino como abanico de posibilidades interpretativas que se despliegan ante la mirada curiosa, emocionada y atenta del lector.

En el texto minificcional, el desenlace adquiere una importancia capital dado que estos textos de brevedad extrema, requieren de un final sorpresivo, impactante y hasta desconcertante que produzca en el lector asombro, y lo motiven de esta forma, a encontrar posibles rutas para explorar los múltiples sentidos a los que el texto apuesta desde lo surrealista, fantástico, la ironía, parodia, el suspenso y humor; estrategias y recursos que le permiten al texto minificcional desmontar la lógica hasta constituirse en un territorio indómito, fragmentario y fronterizo amparado en una estética de ruptura que interpela permanentemente al lector, juega con él y lo desplaza caleidoscópicamente por lo veloz y efímero de un tiempo que se capta en cada instantánea narrativa a través del lente minificcional. Para demostrar este juego de lecturas al cual es invitado el lector, se continuarán analizando los dos textos previamente abordados del libro Los dientes de Raquel de Gabriel Jiménez Emán.

El desenlace en el texto minificcional Los brazos de Kalym es literalmente sorprendente: "Olvidemos eso por ahora y vayamos a dormir-dijo Kalym abrazando a su mujer”. Hay aquí una ruptura total de la lógica, ya que si se arrancan los brazos y de paso, la mujer nota la ausencia de éstos, e incluso, pregunta por ellos, cómo es posible que él luego la abrace. Este desenlace de esquizofrenia, genera algunas perspectivas de lectura: a) pareciese que a modo infantil, la mujer coopera con el acontecimiento imaginario que se inventa Kalym; es decir, le sigue el juego, hace parecer que acepta con absoluta normalidad las reglas absurdas de ese mundo onírico que envuelve al protagonista; b) el absurdo de este acontecimiento solo encuentra cabida precisamente en lo onírico, estamos ante un sueño en el que operan sus propias leyes de lógica y organización; c) el final se conecta con el inicio y, por ende, produce una trama cíclica e intermitente que se mueve entre perder los bazos y mágicamente recuperarlos; y, d) una posibilidad de mentira irracional con la que Kalym intenta persuadir a su mujer, quien en absoluta lucidez lo deja en evidencia al explicarle: "no puede ser - respondió su mujer- pues necesitabas el izquierdo para arrancarte el derecho, pero ya te lo habías arrancado", y al quedar descubierto, Kalym no termina de aceptar su farsa y presenta un nuevo y misterioso argumento: "Ya lo sé mujer, mis brazos son algo muy extraño".

Es curioso observar cómo el autor, luego de generar toda una atmósfera de fantasía y extrañeza, recurre a la lógica para explicar de qué forma Kalym arranca sus brazos y es esa misma lógica la que permite a la mujer romper con ese hechizo de irrealidad, el cual, al desaparecer, deja en evidencia al protagonista y en sorpresa al lector, cuya sorpresa llega a su máxima tensión cuando aparece mágicamente la palabra "abrazando", lo que genera además un clima colapsado por el absurdo y desbordado por el humor lo que ocasiona un estallido colosal en ese juego de intermitencias que durante la pequeña historia se ha debatido entre el sueño y la razón.

Evidentemente, el texto plantea algunas demandas que configuran el ejercicio de un lector implícito, quien deberá jugar con las cartas de fragmentariedad, trasgresión y ruptura de la lógica, a capricho de las coordenadas que el mismo espacio minificcional le impone. De esta forma van surgiendo pistas que 
anuncian el establecimiento de reglas y estructuras propias que exigen un particular modo de lectura, organización y re-creación Para Iser (1987: 70), el lector implícito responde a un proceso de transformación en "el cual se transfieren las estructuras del texto, a través de los actos de representación, al capital de experiencia del lector. Porque esta estructura es la generalizada en la lectura de los textos de ficción". No obstante, el lector real, ese que trae su propio equipaje de lecturas, también apuesta su experiencia al servicio reconstructivo de los sentidos y significados que porta la obra literaria. Se trata pues de un encuentro comunicativo en el cual el texto demarca el rumbo de algunas acciones que entran en completitud con el aporte que hace el lector desde su propia enciclopedia. Desde este lugar de encuentro se fraguan tensiones que permanentemente suscitan ajustes y transformaciones tanto en los múltiples significados desplegados por el texto como en las diversas facetas que derivan del propio acontecimiento lector. En este naufragio de sentidos y de posibilidades de lectura, las únicas tablas de salvación resultan ser la creatividad, imaginación y audacia para comprender la apuesta estética que delinea a cada obra literaria.

Ahora bien, el desenlace de Los dientes de Raquel: "Los dientes volvieron a la boca de Raquel, quien muy hambrienta corrió a pedirle a su mamá que le comprara una manzana”, deja abiertas, de momento, dos posibilidades evidentes de análisis. Por un lado, hay una estructura circular en que el final se estrecha y pareciera ser el inicio del texto; obteniendo de esta forma una relación cíclica infinita; por el otro, esos dientes humanizados vuelven a la boca y se disponen a morder nuevamente una manzana, lo que representaría una calma dentro de la tensión narrativa; es decir, luego de lo sobrenatural, absurdo y extraño (dientes que por sí solos se comen a la manzana y a Raquel), el autor introduce una ruptura radical en la lógica secuencial y en el mismo universo ficcional: Raquel hambrienta compra una manzana. De esta forma observamos que el clima fantástico generado desde las primeras frases, es cortado ilógicamente por una secuencia que intenta recobrar la coherencia, generando una tercera posibilidad de lectura, así pareciera que Raquel estaba dormida y ahora, de repente, despierta de una alucinante pesadilla.

En este punto, el lector opera rellenando los vacíos que posee el texto, a partir de: sus particulares visiones de mundo, sus competencias y experiencias de lectura, las pistas y claves que proporciona el mismo tejido narrativo, develadas en el ejercicio lector, de las reacciones que el mundo re-creado suscite; $y$, de las múltiples y dinámicas formas en que pueden ser organizados los diversos lugares de lectura. Al respecto, resultan esclarecedoras las consideraciones de Iser (1987: 161) cuando afirma que el texto "es estético en cuanto que lo ha producido el lector mediante la dirección trazada por la constelación cambiante de puntos de vista". De este planteamiento desentrañamos tres ideas importantes: el texto es una unidad susceptible de los desafíos interpretativos y de las rutas re-significantes que el lector incorpore a su particular mapa de lectura; en el fenómeno literario opera un acuerdo implícito de acto lúdico, por tanto, el lector debe jugar con las cartas que el mismo texto le proporciona; por último, el mundo posible que proyecta la obra literaria, sustrae al lector de la comodidad de sus certezas, lo sacude y le hace advertir que se encuentra frente a un universo que se mueve de acuerdo a sus propias lógicas, reglas y estrategias, siendo este terreno de autonomía y pacto ficcional, el que suscita, precisamente, múltiples posibilidades de lectura. En todo este engranaje, resulta evidente el rol activo que debe desempeñar el lector para encontrar la salida a ese laberinto textual, identificar sentidos y significados proyectados por el universo narrativo; y, reconocer las coordenadas que caracterizan el mundo posible recreado en la obra literaria.

En este sentido, puede afirmarse, a propósito de los desenlaces examinados que, por ejemplo, en Los brazos de Kalym se produce un final sorpresivo y ambiguo a la vez, en el cual al "abrazar a su mujer" se 
resuelve el conflicto de la pérdida de los brazos. Pareciera entonces que se produce un juego en el que por un instante, falta el sentido común y luego, en intermitencias, se retoma el sentido lógico. En el caso de Los dientes de Raquel, el conflicto queda resuelto cuando los dientes vuelven a la boca de Raquel y ésta se dispone a pedir una manzana. Hay aquí una circularidad narrativa que, uniendo las polaridades, permite que la historia comience y termine en un ciclo infinito.

Observamos cómo estos textos minificcionales (y ocurre en todo el fenómeno literario) se concretan en el acto de la lectura. Por lo tanto, en el lector se activan un conjunto de operaciones que actúan como "brújulas" para organizar las pistas que conducen a la producción de sentidos y significados. En este juego reconstructivo de la experiencia lectora, opera lo que Jauss (1976: 78) denominaría "efecto o experiencia estética", al respecto afirma: "La comunicación literaria mantiene, en todas sus dependencias funcionales, el carácter de experiencia estética, siempre y cuando la actividad poiética [habilidad reconstructiva del texto], aisthésica [habilidad para advertir el abanico de significados que el texto proyecta] o catártica [liberación de los horizontes de expectativas en el circuito comunicativo], no deje de producir un comportamiento placentero". Estamos pues en presencia de un proceso de recepción que al ser inacabado, reactualiza permanentemente la acción del sujeto lector para advertir además de los sentidos, efectos, recursos y estrategias a los que la obra apuesta en una suerte dinámica que estrecha el interés comunicativo con el interés creativo.

En este sentido, el panorama textual le permite al lector actuar, rellenar los vacíos y actualizar los significados; en ese actuar (que primero se complementó con el creador) se fue desdibujando el autor y ahora queda el lector (desde la vigencia y legitimidad de su autonomía productora de sentidos) con su propia obra: un abismo en miniatura (inacabado en posibilidades de recepción) en el cual las imágenes son sucesiones de una simultaneidad vertiginosa que ahora establecen con el lector un nuevo pacto ficcional: el juego.

Es evidente que las últimas frases no son solo las instancias del desenlace, son además los mecanismos que crean una atmósfera de tensión, ironía, humor, suspenso, lo que hace posible un encuentro intenso que articula todos los elementos narrativos y estrategias ficcionales, sustentando de este modo al pequeño universo narrativo. De esta forma, el relato minificcional estaría caracterizado por la economía del lenguaje, lo fragmentario, el alto poder de sugerencia, predominio del absurdo en una relación lúdica, surrealista, paródica y onírica; y, por la dimensión abismal, fantasiosa e insólita que mueve todas las piezas del texto minificcional, atrapando desde el asombro, la sorpresa y lo desconcertante, la expectativa y curiosidad del lector.

El género minificcional alcanza su auge y desarrollo dentro de un contexto estético vecino a la postmodernidad, no es azaroso entonces que lo extraño, fragmentario, lúdico y trasgresor sean sus rasgos más evidentes, amparados en nuevos escenarios de producción y recepción del texto literario que auguran a su vez, nuevas instancias de composición narrativa e inéditos lugares de lectura movidos entre construcción de sentidos y diversión. Los textos minificcionales, por su brevedad extrema, más que cualquier otro género literario, se encuentran plagados de vacíos narrativos, su economía lingüística es compensada con la abundancia de lugares indeterminados que implican, necesariamente, una cooperación del destinatario para dar sentido comprensivo, descifrar los complejos temáticos y narrativos; $y$, moverse entre un conjunto de estrategias discursivas que le asignan su carácter abismal a ese universo minificcional. Este tejido conceptual podemos precisarlo en tres construcciones: la mi- 
nificción exige nuevos lugares de lectura en los que la actividad receptora ocupa un lugar fundamental; los desenlaces del texto minificcional apuestan tanto al humor, absurdo, parodia e ironía, como a la multiplicidad de significados; y, estamos ante textos muy breves que paradójicamente resultan ser amplios en posibilidades interpretativas.

\title{
3. Los dientes de Raquel: entre lo fantástico y el suspenso
}

\author{
Interesa atrapar el universo en una línea. \\ Gabriel Jiménez Emán
}

En la mayoría de los textos minificcionales que figuran en la obra Los dientes de Raquel del escritor venezolano Gabriel Jiménez Emán, se observa un fuerte carácter fantástico expresado en un conjunto de situaciones que escapan a la lógica y solo encuentran asidero en el terreno de lo extraño y absurdo. Por ejemplo, en el ya mencionado texto Los dientes de Raquel, tenemos un argumento central que se concentra en la caída de unos dientes que, humanizados y con absoluta autonomía, se comen a la manzana y también a la protagonista; o, el caso de Los brazos de Kalym, en donde observamos cómo el conflicto de arrancarse los brazos y lanzarlos a un abismo, bordea una zona límite de inexplicables y extrañas circunstancias. En ambos textos, la anécdota narrada se desplaza de la fantasía a la realidad con absoluta normalidad, quizá sea esta la causa del asombro y el desconcierto, siendo el humor la única tabla de salvación. Como vemos en ambos textos minificcionales, el acontecimiento y toda la atmósfera narrativa es de orden fantástico. En este planteamiento, resultan a propósito las consideraciones de Louis Vox- citado por Todorov (1972: 36)- quien afirma: "El relato fantástico[...] nos presenta por lo general a hombres que, como nosotros, habitan el mundo real, pero que, de pronto, se encuentran ante lo inexplicable".

Así, Kalym y Raquel son seres humanos que bien pueden entrar en lo cotidiano; pero, de pronto, y de forma inexplicable, Raquel pierde sus dientes al morder una manzana y Kalym arranca sus brazos y los lanza al abismo. Ambos sucesos producen una atmósfera de extrañeza que es explicable solo desde la imagen de lo maravilloso-fantástico. En ambas historias tendría vigencia lo que plantea Todorov (1972: 36) en torno a lo fantástico: "Aparece el "misterio", lo "inexplicable", lo "inadmisible" que se introduce en la "vida real" o en el "mundo real" o bien en la inalterable legalidad cotidiana".

En este sentido, se puede constatar que el desenlace del texto minificcional Los brazos de Kalym, se corresponde con lo que Todorov (1972) denominó fantástico-extraño, ya que los acontecimientos sobrenaturales al final son razonados por la mujer, proporcionando de esta forma una posible explicación que deja en evidencia una "mentira". Se lanza con audacia y lucidez un razonamiento lógico que paradójicamente no nos devuelve a la realidad, sino que nos abstrae por completo de esta, cuando finalmente nos enteramos que Kalym, el que lanzó sus brazos a un abismo, ahora abraza a su mujer. Por su parte, en el desenlace del texto minificcional Los dientes de Raquel, aparece una situación paradójica, en que lo irreal se presenta como una posible solución lógica, lo cual entraría en el terreno de lo que el mismo Todorov (1972) llamó fantástico-maravilloso, ya que el autor no recurre a una posible orientación explicativa, sino que abre el 
abanico de la fantasía y entonces lo sobrenatural se acepta tal como es; de hecho, la misma solución es de naturaleza sobrenatural (los dientes volvieron a la boca de Raquel), aunque lo que cierra el texto retome "aparentemente" la lógica extraviada desde la primera frase. En otras palabras, mientras que en Los brazos de Kalym hay una lógica "posible" que soluciona el conflicto, en Los dientes de Raquel, hay un hecho sobrenatural que suplanta a otro. Es evidente en ambos textos minificcionales que lo fantástico forma parte de un rompecabezas (de rupturas y límites) en el cual figuran además otras piezas como el juego, humor, la ironía, parodia y lo absurdo. Todos estos elementos hacen posible el collage que se expresa simultánea y fragmentariamente en ese abismo narrativo que es la minificción.

El síntoma de todos los textos minificcionales compendiados en el libro Los dientes de Raquel de Gabriel Jiménez Emán es esa atmósfera de extrañeza que suscita cada pequeño universo narrativo, cuya atmósfera es vehiculada desde una búsqueda fantástica que, llevada a extremo, se proyecta en lo absurdo, inexplicable e ilógico. Definitivamente, estos textos rompen con los cánones literarios, con la lógica, con las definiciones.... en fin, se instalan en un terreno de permanentes transiciones de ruptura, fragmentariedad y parodia.

Ahora bien, en los dos textos minificcionales que se han venido comentando a lo largo de este documento, se observa que la tensión narrativa y la atmósfera se vienen tejiendo a través de un suspenso que se dosifica progresivamente en la dilación del texto. Para Barrios (1994) el proceso de dosificación está compuesto por dos fases: retardamiento y reactivación. Así, por ejemplo, en el caso de Los dientes de Raquel, se nos presenta un conflicto fantástico que desemboca, obviamente, en la perplejidad del absurdo que se alimenta progresivamente en un suspenso que se retarda con escenas como "fue a su casa con la boca sangrando a avisarle a su mamá"; pero que posteriormente se reactiva a pasos agigantados cuando la mamá se encuentra con que "los dientes se habían comido la manzana" o cuando, "los dientes se levantaron y se comieron a Raquel y a la mamá". Por su parte, en Los brazos de Kalym, el conflicto de arrancarse los brazos y lanzarlos al abismo se va retardando cuando en el diálogo aparecen intermitencias como: "tendrás que ir a buscarlos; vas a necesitarlos para el almuerzo. ¿Dónde están? - En un abismo, muy lejos de aquí"; sin embargo, se reactiva cuando Kalym describe la forma en que los ha arrancado y cuando la mujer devela la mentira. Evidentemente, la reactivación llega a un clímax de impulsos y tensiones, en el momento intenso e inexplicable en el que Kalym abraza a su mujer.

Como observamos, el suspenso toma partido de esa corriente fantástica que produce un clima de sueño y extrañeza en el texto minificcional. El lector se ve envuelto en un conjunto de juegos y acertijos que lo atraen, además está atento gracias a unas fuertes dosis de suspenso y a un conjunto de pistas que irremediablemente lo obligan a transitar por ese laberinto discursivo, cuya salida será la posibilidad de instalarse en alguna, de las tantas lecturas posibles que se vislumbran en ese horizonte textual. Es en definitiva un transeúnte que debe desplazarse con cautela por esas zonas límites en que la realidad se confunde con la fantasía y el suspenso con el éxtasis.

Gabriel Jiménez Emán reincide a lo largo de su obra, y con énfasis, en el libro Los dientes de Raquel, en el tema fantástico. De allí que sus argumentos se construyan desde una realidad que es adulterada, unas situaciones surrealistas, un panorama alucinatorio y fantasmagórico; $y$, un cruce anárquico entre lo racional y el absurdo. Sus personajes y universos narrativos se pasean por lo onírico, apuestan al juego, desequilibran todas las certezas, se sustentan en la risa irónica que deriva de la parodia, son trasgresores y fragmentarios, apuestan por una dicotómica relación entre finitud, brevedad e infinitud; en fin, son 
abismos en miniatura, mundos minificcionales que aportan a la literatura venezolana una genuina propuesta estética.

\section{Comentarios finales}

Gabriel Jiménez Emán es una referencia obligada de lo que ha sido la minificción en Venezuela. Con su libro Los dientes de Raquel se aventuró en una peculiar forma de hacer literatura de la que no se separará jamás. Su madurez artística y profunda sensibilidad han alimentado su vocación para la escritura, la teorización de estrategias y formas de composición; y, para el oficio de antologista y promotor literario. Su sentido subversivo lo llevan a pasearse por una ambigüedad genérica, temática y estética que le permiten instalarse en esa libertad expresiva, propia del género minificcional, que se burla, disuelve y fragmenta.

Su propuesta narrativa construye un espacio ficcional que no se encasilla en una sola propuesta, la brevedad le sirve para jugar con multiplicidad de sentidos y atraer al lector, sus atmósferas oníricas y fantásticas logradas a través del suspenso, inicios que atrapan y finales que golpean demuestran su habilidad para jugar con estrategias y recursos narrativos; sus universos minificcionales son abismales, paradójicos y alternos. Tal como lo afirmara Várderi (1982), Jiménez Emán realiza un trabajo atractivo en el que presenta la realidad frente a la irrealidad distanciadas por una finísima línea que, lejos de separar a una de la otra, las une para demostrar lo indisoluble de una relación que vive en nosotros.

Con sus universos minificcionales, la obra de Gabriel Jiménez Emán apuesta por generar múltiples perspectivas interpretativas que se alimentan básicamente de una fuente inagotable de ficción imaginaria, la cual es capaz de suscitar las más variadas asociaciones, estructuras, diversificaciones, estrategias y posibilidades narrativas que no hacen más que revelar una escritura compleja que, aunque se recrea en lo breve y en lo aparentemente sencillo, no deja de asombrarnos por las innumerables miradas de lectura a partir de esos pequeños fragmentos o textos minificcionales que se burlan de la realidad y dejan al lector en la perplejidad de un asombro que emerge del absurdo. De allí que sus relatos constituyan una mínima instantánea del vértigo que produce la recreación de lo insólito en una zona límite en que se cruza la razón y la locura. Al respecto, afirma Zambrano (1991: 17) lo siguiente:

La cotidianidad se trastoca con frecuencia gracias a los sueños. La realidad se enfrenta al mundo onírico para descubrir lo subterráneo, lo inconsciente del diario vivir, y el escritor Gabriel Jiménez Emán sabe de esto, porque él juega con el lenguaje, con la fantasía y el humor para adentrarse en lo grotesco que no deja de ser poético.

En definitiva, Gabriel Jiménez Emán es un escritor minificcional, sus obras expresan estrategias, elementos y características propias de este género emergente que se asume como pretexto para crear universos fantásticos y surrealistas movidos por una atmósfera alucinatoria y fantasmal. Es cultivador de un ejercicio escritural caracterizado por la extrema brevedad, el cruce genérico y una temática obsesivamente vinculada con el absurdo y el juego, elementos, por cierto, que le permiten al lector reconstruir permanentemente las pequeñas historias a partir de los retazos; el diseño obtenido nunca es definitivo, sus textos tendrán tantas posibilidades de lectura como lectores se acerquen a ellos. Estos ingredientes hacen que la lectura de su obra cautive, que sea divertida, fresca y amena. Para completar esta afirmación, bastan las palabras de Miranda (1988: 4) quien refiere lo siguiente: 
La fidelidad de Gabriel Jiménez Emán a cierto humor entre fantástico y fantasioso, su pericia para ¿inventar o sentir? las fisuras de lo real cotidiano; su capacidad de crear atmósferas levemente angustiosas; su afición a paradojas; su gusto por el absurdo, todo esto, y una indiscutible...fantasía de bolsillo... [le] ha [permitido] producir... una obra peculiar.

Es evidente que la obra de este escritor no solo refleja una habilidad creadora expresada en emoción que contagia y en recreación de universos caóticos, incoherentes y fantásticos; sino que, con su propuesta estética, introduce cambios y rupturas en la literatura venezolana, contribuyendo específicamente al devenir del cuento y a la emergencia del género minificcional. Esa mirada poco convencional de una escritura laberíntica que yuxtapone con extrañeza la lógica y la incoherencia, seduce con el fragmento, juega con las ironías y paradojas, se burla de los límites, parodia toda certeza y suscita en el vértigo de la simultaneidad e infinitud, un ideal de ruptura que se consolida en la multiplicidad de lecturas posibles; todo ello, en definitiva, hace de la obra de Jiménez Emán, un genuino y peculiar abismo en miniatura.

\section{Referencias}

Barrios, Alba. 1994. Aproximación al suspenso. Caracas: FUNDARTE.

Gómez, Francisco. 1996. La crítica literaria del siglo XX. Madrid: EDAF.

Illas, Wilfredo. 2004. La minificción como estrategia discursiva en Los dientes de Raquel de Gabriel Jiménez Emán. Tesis de Maestría, Valencia-Venezuela: Universidad de Carabobo.

Iser, Wolfgang. 1987. El acto de leer. Teoría del efecto estético. Madrid: Taurus.

Jauss, Hans-Robert. 1976. La literatura como provocación. Barcelona: Península.

Jiménez, Gabriel. 1973. Los dientes de Raquel. Caracas: Monte Ávila Editores.

Jiménez, Gabriel. 1982. Gabriel Jiménez Emán: mis libros son pecados de los que no me arrepiento. El Universal. 26 de noviembre.

Miranda, Julio. 1988. Un libro entre dos estaciones. El diario de Caracas. 31 de Julio.

Rojo, Violeta. 2009. Breve manual (ampliado) para reconocer minicuentos. Caracas: Equinoccio, Universidad Simón Bolívar.

Todorov, Tzvetan. 1972. Introducción a la literatura fantástica. Buenos Aires: Tiempo Contemporáneo. Várderi, Ángel. 1982. ...sobre geometría: la línea. El Nacional-Papel literario. 27 de diciembre.

Zavala, Lauro. 2005. La minificción bajo el microscopio. Bogotá: Fondo editorial UPN

Zambrano, Miguel. 1991. Tras el absurdo de lo cotidiano, está la pluma de Jiménez Emán. El Nacional. 18 de mayo. 